\title{
Giant extra-articular synovial osteochondromatosis of the left proximal thigh: A case report
}

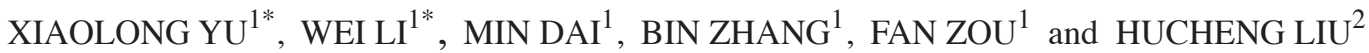 \\ ${ }^{1}$ Department of Orthopedics; ${ }^{2}$ Multidisciplinary Therapy Center of Musculoskeletal Tumors, \\ The First Affiliated Hospital of Nanchang University, Nanchang, Jiangxi 330006, P.R. China
}

Received November 8, 2014; Accepted July 21, 2015

DOI: 10.3892/ol.2015.3746

\begin{abstract}
Extra-articular synovial osteochondromatosis is a rare disease. The present study describes the case of a 46-year-old female who suffered from extra-articular synovial osteochondromatosis of the left proximal thigh with limited hip movement. The patient underwent a total tumor resection and recovered well. The tumor was $15 \times 14 \times 5 \mathrm{~cm}^{3}$ in size and located in the muscle gap. After a 3-month follow-up, the patient's left hip motion was improved and a computed tomography scan demonstrated no evidence of recurrence. However, the long-term efficacy of this procedure requires continuous observation of the patient. To the best of our knowledge, this is the first case of a giant extra-articular synovial osteochondromatosis of the proximal thigh muscle gap.
\end{abstract}

\section{Introduction}

Synovial chondromatosis (SC) has a benign clinical course characterized by cartilaginous metaplasia within the synovial membrane, resulting in the formation of multiple cartilaginous nodules within the synovium $(1,2)$. These nodules can then ossify or calcify leading to extrusion from the synovium leaving osteochondral loose bodies within the joint space or extra-articular soft tissues, but bony erosion is rare (3). SC usually has intra-articular involvement of the joints, including the hip, knee, ankle, elbow, wrist and shoulder joints (4). Extra-articular involvement is rare and mainly observed in a synovial sheath or bursa of the hand and foot (5). The current study presents a case of synovial osteochondromatosis of the left proximal thigh muscle gap in a 46-year-old female. This study was approved by the Ethical Review Committee of The

Correspondence to: Professor Min Dai, Department of Orthopedics, The First Affiliated Hospital of Nanchang University, 17 Yong Wai Zheng, Nanchang, Jiangxi 330006, P.R. China E-mail:250132519@qq.com

*Contributed equally

Key words: extra-articular, synovial osteochondromatosis, left proximal thigh, surgery, pathology
First Affiliated Hospital of Nanchang University Medical School (Nanchang, Jiangxi, China), and informed consent was obtained from the patient.

\section{Case report}

A 46-year-old female presented to the Department of Orthopedics, The First Affiliated Hospital of Nanchang University (Nanchang, China) on June 24, 2014, with the chief complaint of painful swelling of the left proximal thigh. The swelling had first appeared 3 years previously and had become aggravated during the last 6 months. The patient had no history of injury, past medical illnesses or family history that were associated. In the general physical examination, limited motion in the left hip was observed, with paresthesia in the left lower extremity.

In a further examination, a well-defined, lobular, tender and firm soft-tissue mass was found over the left proximal inner thigh, and the test for hip instability was negative. Plain radiographs indicated a huge mass shadow medial to the left proximal thigh, which contained multiple radiopaque calcified bodies. No visible destruction of the surrounding bone was shown (Fig. 1A). Computed tomography (CT) revealed an irregular mixed density mass shadow containing a certain degree of punctate calcification in the gap between the anterior and posterior muscles of the left proximal inner thigh (Fig. 1B). However, the articular surface of the hip joint was intact and these small calcified bodies did not migrate into the hip joint cavity. Enhanced CT showed slight peripheral enhancement of the mass. In addition, no distant metastases were observed. Furthermore, magnetic resonance imaging (MRI) was performed to evaluate the giant mass. Axial T1-weighted images showed a low-signal intensity and axial T2-weighted images showed a high-signal intensity containing certain areas of punctate low-signal intensity (Fig. 1C and D). T2-weighted imaging with fat suppression also showed high-signal intensity. Based on this information, SC was considered with regard to the diagnosis of the patient.

Based on the exclusion of surgical contraindications, orthopedic tumor surgeons performed surgery to resect the tumor. The patient was placed in a floating supine position with disinfected and paved sterile drapes arranged routinely around the left proximal thigh to expose the surgical field following successful epidural anesthesia. First, surgery via a medial approach to the hip joint was performed, with a $\sim 15-\mathrm{cm}$ 

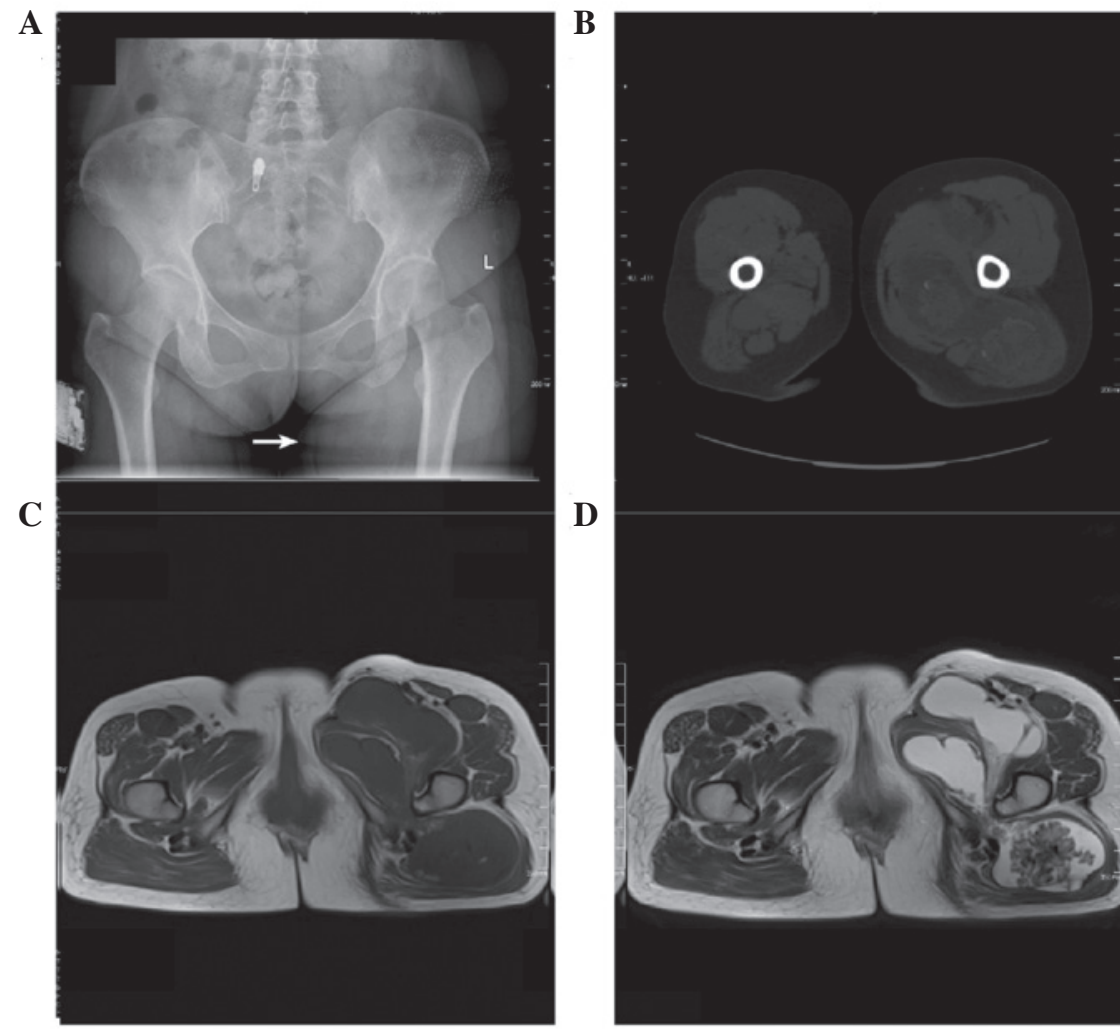

Figure 1. Pre-operative imaging examination. (A) Plain radiographs demonstrating a huge, oval, calcified mass that contained multiple radiopaque bodies, located medial to the left proximal thigh (white arrow). (B) Computed tomography scan showing an irregular mixed density mass located in the gap between the anterior and posterior muscles of the left proximal inner thigh. Axial (C) T1-weighted images showing a homogeneous, low-signal intensity and (D) axial T2-weighted images showing a high-signal intensity containing certain areas of punctate low-signal intensity.
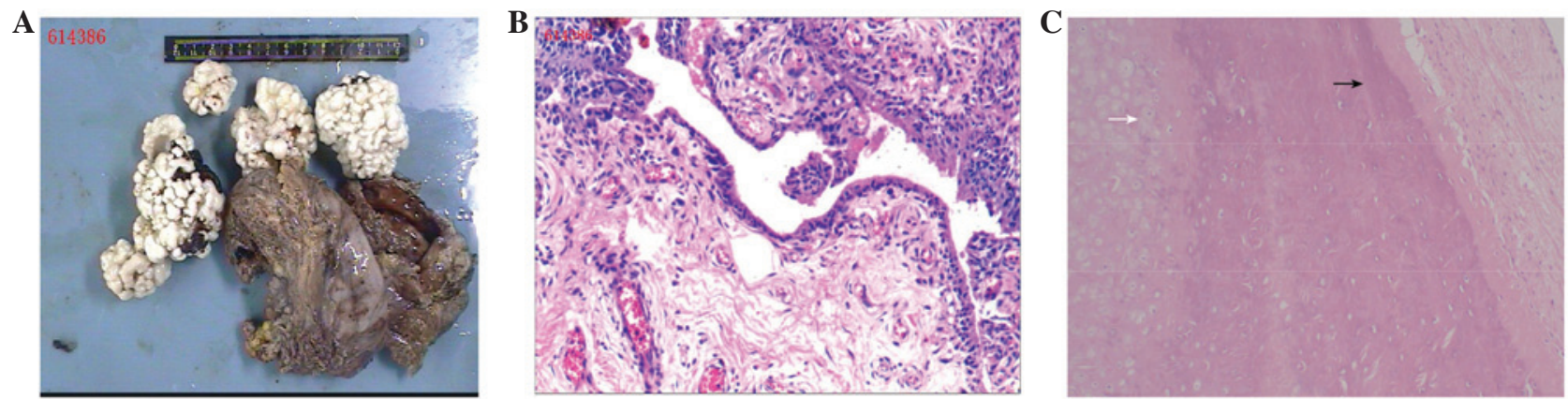

Figure 2. Post-operative histological observations. (A) Gross appearance of the huge, smooth-surfaced, dark-brown membrane-like manifestations and several loose bodies after removal, $15 \times 14 \times 5 \mathrm{~cm}^{3}$ in size. (B) Membrane-like manifestations demonstrating mature synovial tissue (HE staining; magnification, $\mathrm{x} 100$ ). (C) Loose bodies showing mature cartilaginous tissue containing multiple chondrocytes (white arrow) and ribbon calcification (black arrow) (HE staining; magnification, x100). HE, hematoxylin and eosin.

long incision. Furthermore, the subcutaneous tissue, superficial fascia, deep fascia and adductor group of muscles were separated layer by layer until the femoral artery, femoral vein and femoral nerve were observed. The nerve and vessel above were compressed slightly by the huge tumor, but appeared to be intact. The tumor was milk white, located from the front to the back of the left proximal inner thigh, and included several cauliflower-like, firm, cartilaginous nodules. The anterior region of the tumor was excised completely. In order to excise the posterior region of the tumor, a posterior approach to the hip joint was applied. The tumor was observed near the ischiadic nerve, which was intact. Through separation of the subcutaneous issue, superficial fascia and gluteal fascia, the tumor was more specifically located in the gap between the gluteus maximus and medius. The posterior region of the tumor was excised completely. Intraoperative tissues were extracted to perform a pathological examination. A wound drainage tube was placed and each layer of tissue was sutured strictly after complete hemostasis. In addition, the estimated blood loss volume was $300 \mathrm{ml}$ and there was no blood transfusion in the whole treatment process.

The gross pathological examination revealed large, smooth-surfaced, dark-brown membrane-like manifestations and several loose bodies. The irregular tissue was $\sim 15 \times 14 \times 5 \mathrm{~cm}^{3}$ in size (Fig. 2A). Upon hematoxylin and eosin staining, the membrane-like manifestations were revealed to 
be mature synovial tissue (Fig. 2B). The histopathological findings of loose bodies ultimately revealed mature cartilaginous tissue with calcification. The chondrocyte nuclei were normal without atypical changes. There were no definite binucleate cells and no mitotic chondrocytes observed. No necrosis or bone destruction was found (Fig. 2C). The diagnosis of primary $\mathrm{SC}$ was confirmed on the basis of these findings. There was no evidence of chondrosarcomatous transformation.

The patient was discharged without any complications 1 week after the total excision surgery. At the time of the 3 -month follow up, the patient was completely free from pain during daily activities and a normal range of motion was present in the left hip joint. No evidence of recurrence was noted during the 3 months after surgery.

\section{Discussion}

$\mathrm{SC}$ is a benign condition that usually occurs among individuals $>40$ years old, with a predilection for males. Among the population of SC patients, the ratio of males to females is $2: 1(6,7)$. $\mathrm{SC}$ is characterized by metaplasia and formation of multiple cartilaginous nodules in the synovial membrane of the joints, tendons and bursae (1,2,7). Typically, it usually involves the large joints. The knees are most commonly involved and account for $60-70 \%$ of cases, with the elbows, hips and shoulders as the other common sites $(5,8)$. Although the etiology is thus far unknown, certain data has suggested a neoplastic origin with chromosome 6 abnormalities (9). There is an extraordinarily low risk of malignancy with SC, however, a case study has confirmed the coexistence of chondrosarcoma with SC (10).

SC can be classified into primary and secondary forms. Primary SC is associated with the benign reactive metaplasia of the synovial membrane $(11,12)$. Milgram divided this into three phases. Phase one encompasses active synovial disease without joint loose bodies. Phase two involves a transitional phase with osteochondral nodules in the synovial membrane and free floating in the joint space. Phase three reveals several free osteochondral bodies with intrasynovial disease (13). Secondary SC is associated with the setting of pre-existing joint pathology, such as trauma, osteonecrosis, tuberculosis, rheumatoid arthritis, synovitis, osteoarthritis, osteochondritis dissecans and neuropathic arthropathy $(11,12)$. The two forms of SC have typical histopathological differences. In primary lesions, cartilage nodules and loose bodies manifest as irregular nests, usually with binucleated cells formed by sporadic diffuse calcification and metaplastic cartilage. By contrast, in secondary lesions, calcifications are band-like with uniform, evenly distributed chondrocytes; furthermore, fragments of subchondral bone or articular cartilage may be present at the center of loose bodies $(14,15)$.

The disease process includes the synovium of a joint, bursa or tendon sheath undergoing metaplasia, nodular proliferation, hyperplasia, hyaline or myxoid changes and fragmentation. These fragments may break off from the synovial surface into the joint, and will continually grow, calcify or ossify when loose bodies have formed, subsequently starting to lock or irritate the joint. Other fragments may embed within the proliferating synovium or extend into the surrounding soft tissues $(7,13)$. Multiple intra-articular loose bodies can result in degenerative osteoarthritis of the joint; this may cause the mechanical destruction of the articular cartilage (7). Clinically, these patients present with progressively painful, swollen and growing palpable masses on affected joints. Limitations in movement and locking of the joints can also be caused (16). Although the large soft-tissue mass was located in the muscle gap in the present study, the patient presented with limited movement of the left hip, swelling and progressively worsening pain around the left proximal thigh. This may have been a result of extrusion of the periphery of normal tissue.

Extra-articular synovial osteochondroma is difficult to detect during the early stages (17). The radiological appearance is dependent on the disease stage and the extent of cartilaginous nodule calcification.

If the extra-articular fragments are adequately calcified, a diagnosis is easily made according to plain radiographic examination and CT scan, as shown in the present patient (Fig. 1). With non-calcified fragments, MRI scans are required. MRI is useful in the early phase of SC, as radiography is only able to reveal a soft-tissue density mass prior to the occurrence of calcification or ossification (5). In the present patient, MRI was performed to evaluate the status of the ligaments and adjacent articular cartilage around the left hip joint.

Surgical excision has been considered as the preferential treatment to relieve pain, limit osteoarthritis development and histologically confirm the diagnosis (18). The treatment of choice involves the excision of loose bodies and an extensive synovectomy regardless of whether the synovial osteochondroma is intra- or extra-articular $(19,20)$. In the present case, mass excision with extensive synovectomy was performed due to the large size of the mass and the irritation to the hip joint.

Following surgical treatment, the patient was symptom-free at the 3-month follow-up. Although the condition is benign and recurrence is not usually observed, we suggest that the follow-up of such patients should be performed for observation of any malignant changes.

\section{References}

1. Nakashima H, Sugiura H, Nishida Y, Yamada Y and Ishiguro N: Synovial osteochondromatosis of the carpometacarpal joint. Am J Orthop (Belle Mead NJ) 36: E151-E152, 2007.

2. Burrafato V, Campanacci DA, Franchi A and Capanna R: Synovial chondromatosis in a lumbar apophyseal joint. Skeletal Radiol 27: 385-387, 1998.

3. Birchall D, Khangure MS and Spagnolo DV: Vertebral synovial osteochondromatosis with compressive myelopathy. Spine (Phila Pa 1976) 24: 921-923, 1999.

4. Lohmann CH, Köster G, Klinger HM and Kunze E: Giant synovial osteochondromatosis of the acromio-clavicular joint in a child. A case report and review of the literature. J Pediatr Orthop B 14: 126-128, 2005.

5. Doral MN, Uzumcugil A, Bozkurt M, Atay OA, Cil A, Leblebicioglu G and Tetik O: Arthroscopic treatment of synovial chondromatosis of the ankle. J Foot Ankle Surg 46: 192-195, 2007.

6. Maier D, Izadpanah K, Jaeger M, Ogon P and Südkamp NP: Biceps tenoscopy in arthroscopic treatment of primary synovial chondromatosis of the shoulder. Arthrosc Tech 3: e539-e545, 2014.

7. Lim SJ, Chung HW, Choi YL, Moon YW, Seo JG and Park YS: Operative treatment of primary synovial osteochondromatosis of the hip. J Bone Joint Surg Am 88: 2456-2464, 2006.

8. Davis RI, Hamilton A and Biggart JD: Primary synovial chondromatosis: A clinicopathologic review and assessment of malignant potential. Hum Pathol 29: 683-688, 1998.

9. Buddingh EP, Krallman P, Neff JR, Nelson M, Liu J and Bridge JA: Chromosome 6 abnormalities are recurrent in synovial chondromatosis. Cancer Genet Cytogene 140:18-22, 2003. 
10. Hermann G, Abdelwahab IF, Klein M, Kenan S and Lewis M: Synovial chondromatosis. Skeletal Radiol 24: 298-300, 1995.

11. Kumar A, Aggarwal A and Sahni VK: Primary synovial osteochondroma of a subdeltoid bursa. Indian J Orthop 44: 104-107, 2010.

12. Villacin AB, Brigham LN and Bullough PG: Primary and secondary synovial chondrometaplasia: Histopathologic and clinicoradiologic differences. Hum Pathol 10: 439-451, 1979.

13. Milgram JW: Synovial osteochondromatosis: A histopathological study of thirty cases. J Bone Joint Surg Am 59: 792-801, 1977.

14. Chen A, Shih SL, Chen BF and Sheu CY: Primary synovial osteochondromatosis of the first metatarsophalangeal joint. Skeletal Radiol 31: 122-124, 2002.

15. Khan Z, Yousri T, Chakrabarti D, Awasthi R and Ashok N: Primary synovial osteochondromatosis of the first metatarsophalangeal joint, literature review of a rare presentation and a case report. Foot Ankle Surg 16: e1-e3, 2010.
16. Knoeller SM: Synovial osteochondromatosis of the hip joint. Etiology, diagnostic investigation and therapy. Acta Orthop Belg 67: 201-210, 2001.

17. Kim SH, Hong SJ, Park JS, Cho JM, Kim EY, Ahn JM and Park YS: Idiopathic synovial osteochondromatosis of the hip: Radiographic and MR appearances in 15 patients. Korean J Radiol 3: 254-259, 2002.

18. Hamada J, Tamai K and Saotome K: Secondary osteochondromatosis in the subacromial bursa: A report of two cases and review of the literature. J Orthop Sci 9: 317-322, 2004.

19. Galat DD, Ackerman DB, Spoon D, Turner NS and Shives TC: Synovial chondromatosis of the foot and ankle. Foot Ankle Int 29: 312-317, 2008.

20. Kim SR, Shin SJ, Seo KB, Teong CT and Hyun CL: Giant extra-articular synovial osteochondromatosis of the sinus tarsi: A case report. J Foot Ankle Surg 52: 227-230, 2013. 